\title{
Fabrication and Characterization of Bulk Heterojunction Solar Cells Based on Liquid-Crystal Semiconductive Polymer
}

\author{
Atsushi Suzuki*, Shinichi Ogahara, Tsuyoshi Akiyama, Takeo Oku \\ Department of Materials Science, The University of Shiga Prefecture, Hikone, Japan \\ Email: ${ }^{*}$ suzuki@mat.usp.ac.jp
}

Received September 14, 2012; revised October 15, 2012; accepted October 30, 2012

\begin{abstract}
Bulk heterojunction solar cells based on poly poly(9,9-dioctylfluorene-co-bithiophene) (F8T2) as liquid crystal semiconductive polymer and $\mathrm{C}_{60}$ as electron acceptor were fabricated and characterized. Thermal treatment of the bulk heterojunction films at annealing in the range of glass temperature and liquid crystal transition was performed for tuning optimization with improving the photovoltaic and optical properties. The photovoltaic performance was depended on morphological behavior in active layer at crystal state below glass temperature. The F8T2 thin film worked for electron-donor layer as p-type semiconductor to support charge transfer in active layer. Mechanisms of the photovoltaic properties were discussed on the basis of experimental results.
\end{abstract}

Keywords: Liquid Crystal Polymer; Bulk Heterojunction Solar Cell; Photovoltaic Property; Optical Property

\section{Introduction}

Organic solar cells have their unique advantages of useful applications, low cost, light weight and easy processing $[1,2]$. The organic solar cells based on a low band gap conjugated polymer and fullerene have been studied in recent years $[3,4]$. Advantages of liquid crystal semiconductive polymer have spontaneous self-assembly, relatively high charge mobility, easy deposition by spin coating, roll to roll or ink-jet printing. For instant, liquid crystal semi-conductor polymer of poly(9,9-dioctylfluoreneco-bithiophene) (F8T2) as a block copolymer with alternating dioctylfluorene and bithiophene segments have been applied as hole transporting layer, organic fieldeffect transistors and photovoltaic system [5]. The F8T2 copolymer with bithiophene segments affords good holetransporting properties [6]. The liquid crystal semiconductor polymer of F8T2 depending on thermal treatment has been applied electron devices with charge transfer based on molecular interaction of molecular self-coagulation [7].

Bulk heterojunction organic solar cell of F8T2 and fullerene as p-type and n-type semiconductors has been studied for improving photovoltaic and optical properties. A significant improvement of the photovoltaic performance has been reported by using bulk heterojunction

${ }^{*}$ Corresponding author. thin film in the wide range of spectra. Weight ratio of composition in active layer has been varied to investigate relationship between morphological behavior and the photovoltaic properties [8,9]. Control of morphology of the bulk heterojunction film is important for tuning in optimizing exciton diffusion, charge separation, and electron (hole) transfer to cathode (anode). The photovoltaic properties have been an influence on molecular ordering in crystal phase controlled by heat treatment at glass temperature and liquid crystal transition. Crystallographic structure and morphological behavior of bithiophene-fluorene copolymer and fullerene varied with mole ratio of segment has been studied for improving the photovoltaic performance $[9,10]$.

The purpose in this study is to fabricate and characterrize bulk heterojunction organic solar cell based on liquid crystal semiconductive polymer of F8T2 and fullerenes $\left(\mathrm{C}_{60}\right)$ as electron donor and acceptor. Relationship between the photovoltaic properties and morphological behavior will be focused on tuning for optimization of photovoltaic performance. The thermal behavior on morphological behavior and molecular ordering of the liquid crystal polymer of F8T2 mixed with $\mathrm{C}_{60}$ in the active layer will be investigated by polarized optical mi-croscopy, atomic force microscopy (AFM) and Raman scattering spectra. Mechanism of the photovoltaic and optical properties will be discussed on the basis of experimental results. 


\section{Experimental}

Poly(9,9-dioctylfluorenyl-2,7-diyl)-co-bithiophene (F8T2), poly(3,4-ethylenedioxythiophene)-poly(styrenesulfonate) (PEDOT:PSS) and $\mathrm{C}_{60}$ were used as received from Aldrich Co. Ltd. and Material technologies Research. The molecular structure of $\mathrm{C}_{60}$ and F8T2 were shown in Figures 1(a) and (b). The number and weight average molecular weight of F8T2 was $\mathrm{M}_{\mathrm{n}}>20,000$ and $\mathrm{M}_{\mathrm{w}}=$ 41,126 , as reported by Aldrich Co. Ltd. Mole ratio of (9,9-dioctylfluorenyl-2,7-diyl) and (bithiophene) element parts in F8T2 was 1 to 1 , which indicates alternative copolymer. A repeat of cleaning ITO (A11DU80, AGC Fabritech Co. Ltd. $2 \times 2 \mathrm{~cm}, 10 \Omega / \mathrm{sq}$.) was taken by organic solvents such as acetone, methanol and distilled water. The ITO substrate was dried by $\mathrm{N}_{2}$ gas. The ITO substrate was irradiated with UV lamp for 30 minutes. PEDOT:PSS was spin-coated on the cleaned ITO substrate in glove box under $\mathrm{N}_{2}$ atmosphere. Heat treatment was carried out at $100^{\circ} \mathrm{C}$ for $20 \mathrm{~min}$ in $\mathrm{N}_{2}$ atmosphere.

Bulk heterojunction films of F8T2 $(10 \mathrm{mg})$ and $\mathrm{C}_{60}(10$ $\mathrm{mg})$ solved in $o$-dichlobenzene $(1.0 \mathrm{~mL})$ was prepared on the PEDOT:PSS film based on the ITO substrate by spin coating (MIKASA SPINCOATOR 1H-D7). Heat treatment was carried out at several temperatures for $25 \mathrm{~min}$. The substrate was cooled down in $\mathrm{N}_{2}$ atmosphere. Aluminum (Al) metal was evaporated at thickness of about $100 \mathrm{~nm}$ in an area of $0.16 \mathrm{~cm}^{2}$ on a top of the organic layer. Figure 1(c) shows schematic diagram of the bulk heterojunction solar cells of $\mathrm{F} 8 \mathrm{~T} 2 / \mathrm{C}_{60}$.

(a)

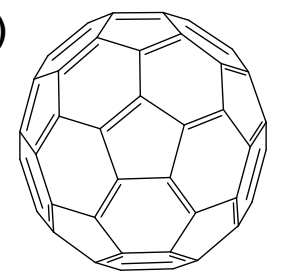

(b)

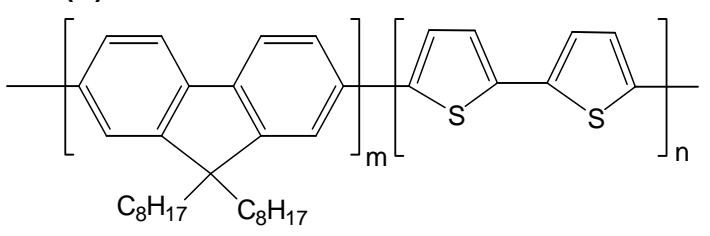

(c)

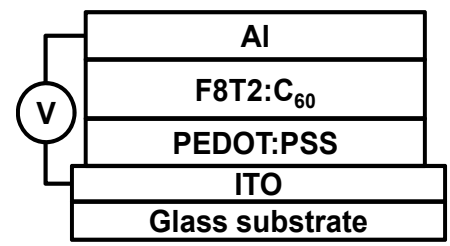

Figure 1. Molecular structures of (a) $\mathrm{C}_{60}$ and (b) F8T2. (c) Schematic diagram of bulk heterojunction solar cells.
Light and dark current density voltage (J-V) characteristics (Hokuto Denko Corp., HSV-110) of the solar cells mentioned above were measured under AM 1.5 $\left(100 \mathrm{~mW} \cdot \mathrm{cm}^{-2}\right)$ irradiation (Sanei Electric, XES-301S) in $\mathrm{N}_{2}$ atmosphere. Optical properties of the heterojunction film were measured by UV-vis spectroscopy (Hitachi U-4100). Surface morphology of the active layer was observed by AFM (SII Nano Technology Inc. SII SPA400). Thermal behaviors of the F8T2 films were measured by DSC (PERKIN ELMER DSC Pyris 1). Raman scattering spectra were recorded with a Laser Raman Spectrometer (NRS-5100, JASCO Co., Ltd.). Raman mode and optical image of the active thin film after annealing at $70^{\circ} \mathrm{C}$ was observed using excitation laser wavelength at $532 \mathrm{~nm}$.

The molecular structure of F8T2 monomer was optimized by CS Chem3D (Cambridge Soft). Molecular orbital calculations were carried out by MOPAC (Fujitsu Ltd.). The isolated molecular structures were optimized by ab-initio quantum calculation using density functional theory using B3LYP/6-31G (d) as basis function (Gaussian 03). The electronic structures with energy levels at HOMO and LUMO were calculated. Active modes in Raman scattering spectra were calculated by DFT/ B3LYP/6-31G (d) using frequency mode.

\section{Results and Discussion}

Thermal behaviors in the range of glass temperature and liquid crystal transition of the F8T2 polymer films were investigated as shown in Figure 2. Thermal transition for F8T2 was conformed to be at $118.5^{\circ} \mathrm{C}, 267.5^{\circ} \mathrm{C}$ and $305.5^{\circ} \mathrm{C}$, which were suitable for a glass temperature $\left(\mathrm{T}_{\mathrm{g}}\right)$, liquid-crystal transition and isotropic transition. These values were closed to be transition points, $128.5^{\circ} \mathrm{C}$, $259.3^{\circ} \mathrm{C}, 314.1^{\circ} \mathrm{C}$, as reported in previous literature [5]. The annealing treatment at several temperatures was carried out for improving the photovoltaic properties and molecular ordering in active layer.

The photovoltaic performance including current voltage curves in the dark and illumination of the $\mathrm{F} 8 \mathrm{~T} 2 / \mathrm{C}_{60}$ bulk heterojunction solar cells were measured as shown in Figure 3. In the case of annealing condition at $70^{\circ} \mathrm{C}$ below glass temperature, the light-induced $\mathrm{J}-\mathrm{V}$ curves in the bulk heterojunction solar cell displayed a slight increase of photo-induced current density in dependence on applied voltage. The light-induced J-V curves of the solar cells indicated the photovoltaic behavior, which had a light induced rectification in strain diode characterization with exponential function of light induced current depending on applied voltage. The photovoltaic performance was improved by annealing treatment at $70^{\circ} \mathrm{C}$ and $100^{\circ} \mathrm{C}$ below glass temperature. However, the performance was reduced with arising annealing temperature at $130^{\circ} \mathrm{C}$ and $190^{\circ} \mathrm{C}$ below liquid crystal transition. 


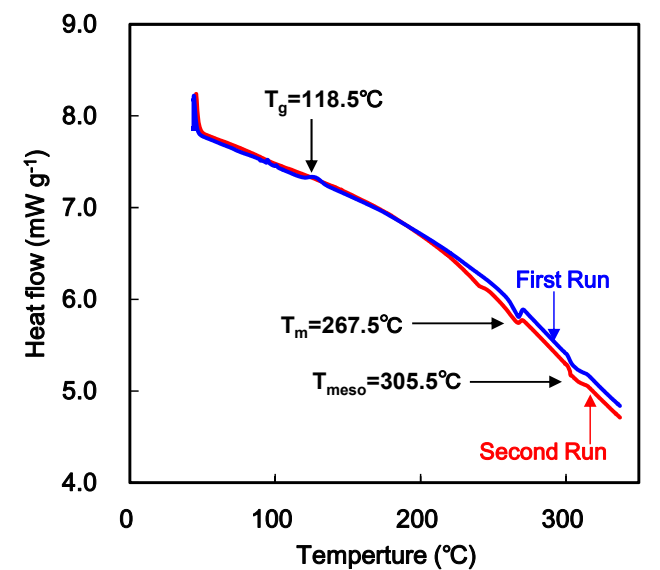

Figure 2. Thermal behavior of F8T2 film by DSC.

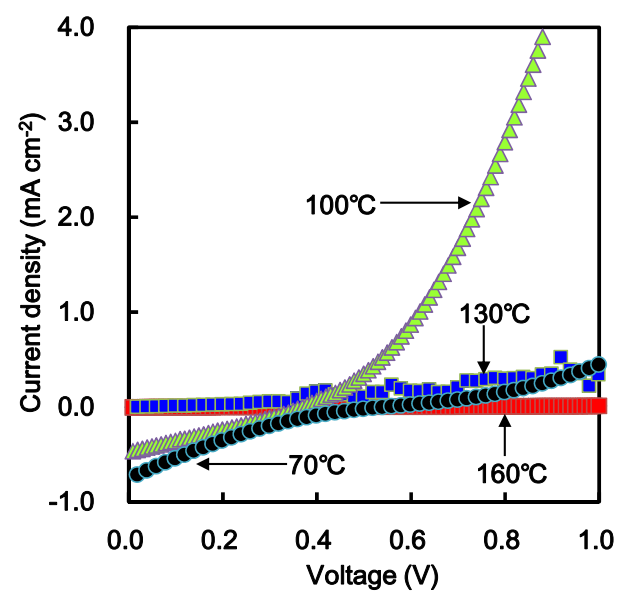

Figure 3. Current voltage curves in illumination of F8T2/ $\mathrm{C}_{60}$ bulk heterojunction solar cells after annealing.

Table 1 shows measured parameters varied with the annealing condition. In the case of the photovoltaic characterization after annealing condition at $70^{\circ} \mathrm{C}$ and $100^{\circ} \mathrm{C}$ below the glass temperature, the measured parameters, open circuit voltage $\left(\mathrm{V}_{\mathrm{oc}}\right)$, short circuit current $\left(\mathrm{J}_{\mathrm{sc}}\right)$, fill factor (FF) and light conversion efficiency $(\eta)$ were obtained to be $0.75 \mathrm{~V}, 0.55 \mathrm{~mA} \cdot \mathrm{cm}^{-2}, 0.16,6.8 \times$ $10^{-2} \%$ for $70^{\circ} \mathrm{C}, 0.37 \mathrm{~V}, 0.48 \mathrm{~mA} \cdot \mathrm{cm}^{-2}, 0.27$ and $4.8 \times$ $10^{-2} \%$ for $100^{\circ} \mathrm{C}$, respectively. At $130^{\circ} \mathrm{C}$ and $160^{\circ} \mathrm{C}$, the experimental results indicate a slight increase of photoinduced current density depending on the voltage, the measured parameters, $\mathrm{V}_{\mathrm{oc}}, \mathrm{J}_{\mathrm{sc}}$ and $\mathrm{FF}$ were obtained to be $2.4 \times 10^{-2} \mathrm{~V}, 5.3 \times 10^{-3} \mathrm{~mA} \cdot \mathrm{cm}^{-2}, 0.15$, for $130^{\circ} \mathrm{C}$ and $0.48 \mathrm{~V}, 6.8 \times 10^{-3} \mathrm{~mA} \cdot \mathrm{cm}^{-2}, 0.16$ for $160^{\circ} \mathrm{C}$. The conversion efficiency, $\eta$ was estimated to be $1.9 \times 10^{-5} \%$ and $5.4 \times 10^{-4} \%$, respectively. In contrast case, device parameters for $\mathrm{F} 8 \mathrm{~T} 2 / \mathrm{C}_{70}$ bilayer were referred to be $0.76 \mathrm{~V}$, $3.07 \mathrm{~mA} \cdot \mathrm{cm}^{-2}, 0.43$ for $100^{\circ} \mathrm{C}, 0.67 \mathrm{~V}, 9.55 \mathrm{~mA} \cdot \mathrm{cm}^{-2}$ and 0.53 for $200^{\circ} \mathrm{C}$ [11]. The conversion efficiency, $\eta$ was reported to be $1.2 \%$ and $3.4 \%$, respectively. The photovoltaic performance for the $\mathrm{F} 8 \mathrm{~T} 2 / \mathrm{C}_{70}$ bilayer was origi-
Table 1. Effect of annealing on photovoltaic performance.

\begin{tabular}{ccccc}
\hline $\begin{array}{c}\text { Annealing } \\
\text { Temp. }\left({ }^{\circ} \mathrm{C}\right)\end{array}$ & $\mathrm{V}_{\mathrm{oc}}(\mathrm{V})$ & $\mathrm{J}_{\mathrm{sc}}\left(\mathrm{mA} \mathrm{cm}^{-2}\right)$ & $\mathrm{FF}$ & $\eta(\%)$ \\
\hline 70 & 0.75 & 0.55 & 0.16 & $6.8 \times 10^{-2}$ \\
100 & 0.37 & 0.48 & 0.27 & $4.8 \times 10^{-2}$ \\
130 & $2.4 \times 10^{-2}$ & $5.3 \times 10^{-3}$ & 0.15 & $1.9 \times 10^{-5}$ \\
160 & 0.48 & $6.8 \times 10^{-3}$ & 0.16 & $5.4 \times 10^{-4}$ \\
190 & 0.32 & $6.0 \times 10^{-3}$ & 0.19 & $3.7 \times 10^{-4}$ \\
\hline
\end{tabular}

nated in the mesoscopic ordering of F8T2 at crystalline state with red-shifted absorption of $\mathrm{C}_{70}$ in the active layer. This state eventually maximized intermolecular interaction at $\pi-\pi$ stacking at crystalline state with a high mobility of F8T2 [11]. The photovoltaic performance of $\mathrm{F} 8 \mathrm{~T} 2 / \mathrm{C}_{60}$ was influenced by molecular disorder cooperated with isotropic state in amorphous phase. The photovoltaic behavior at solid phase below the glass temperature would be originated in charge transfer and molecular interaction between $\mathrm{C}_{60}$ and $\mathrm{F} 8 \mathrm{~T} 2$ in the active layer.

The photovoltaic behavior at thermal condition would be controlled by reduction of carrier hopping process in amorphous phase. The carrier mobility would be reduced by the extent of recombination of carriers at the solid state with amorphous phase. The photovoltaic performance would be based on light-induced carrier separation with extent of charge transfer at crystal state. The photo-voltaic performance and the morphological behavior would be arisen from the extent of recombination of carriers with a lack of crystal domain in the active layer. The morphological behavior after annealing treatment in the range of glass temperature and liquid crystal transition will be investigated by optical absorption, polarizing optical microscopy, atomic force microscopy and Raman scattering spectra.

Effect of annealing treatment varied with thermal condition on the optical properties was investigated. Figure 4 shows UV-vis spectroscopy of the $\mathrm{F} 8 \mathrm{~T} 2 / \mathrm{C}_{60}$ bulk heterojunction at several conditions. At $160^{\circ} \mathrm{C}$ and $190^{\circ} \mathrm{C}$ above the glass temperature, absorbance was entirely increased in the range from $300 \mathrm{~nm}$ to $700 \mathrm{~nm}$. The shoulder absorption slightly appeared near $490 \mathrm{~nm}$. Especially, the absorption was slightly red-shifted near 350 $\mathrm{nm}$. The optical behavior would be originated in a narrow level between HOMO and LUMO, which was based on molecular interaction between $\mathrm{C}_{60}$ and F8T2 at isotropic behavior in amorphous phase.

Polarization behavior of the bulk heterojunction film based on $\mathrm{F} 8 \mathrm{~T} 2 / \mathrm{C}_{60}$ at (a) parallel and (b) perpendicular cross direction is shown in Figure 5. In the all cases after annealing, there was a variety of islands with a wide range of size distribution. In the case at $70^{\circ} \mathrm{C}$ below the 


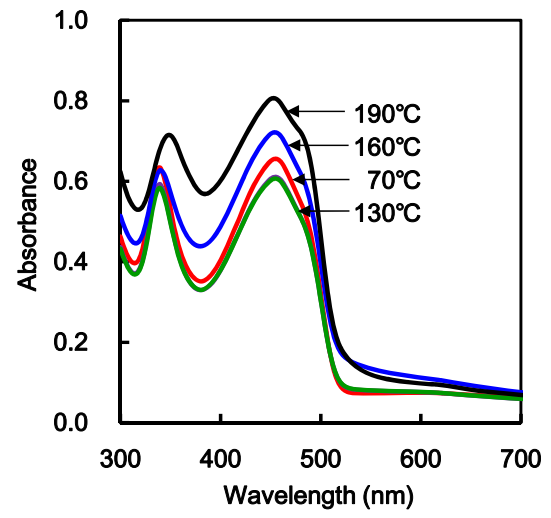

Figure 4. UV-vis spectra of $\mathrm{F8T2} / \mathrm{C}_{60}$ film after annealing.
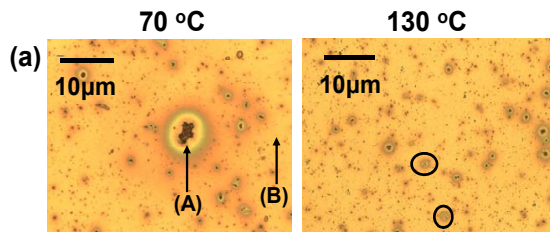

(b)
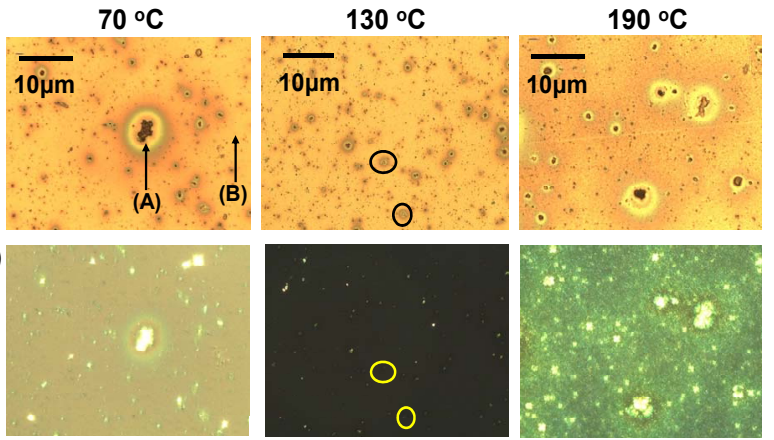

Figure 5. Polarized light optical photomicrographs with (a) parallel and (b) perpendicular polarizing behavior of $\mathrm{FBT}_{2} / \mathrm{C}_{60}$ films after annealing.

glass temperature, it was slightly observed polarizing crystal of the F8T2 island coagulation. While arising temperature above the glass temperature, polarization was gradually disappeared due to isotropic behavior in amorphous phase. The compositions of $\mathrm{F} 8 \mathrm{~T} 2 / \mathrm{C}_{60}$ in the active layer were analyzed by Raman scattering spectra.

Figures 6(a) and (b) show Raman scattering spectra of the active thin film of $\mathrm{F} 8 \mathrm{~T} 2 / \mathrm{C}_{60}$ indicated by arrows (A) and (B) in Figure 5(a). As comparison, the calculated Raman scattering spectra for identifying each active mode of F8T2 monomer were shown in Figure 6(c). From experimental results as shown in Figure 6(a), Raman active mode of the black condensation in the polarized image was obtained as follows: $1035 \mathrm{~cm}^{-1}, 1057$ $\mathrm{cm}^{-1}, 1309 \mathrm{~cm}^{-1}, 1420 \mathrm{~cm}^{-1}, 1458 \mathrm{~cm}^{-1}, 1480 \mathrm{~cm}^{-1}$ and $1580 \mathrm{~cm}^{-1}$. The middle and strong peaks at $1420 \mathrm{~cm}^{-1}$, $1480 \mathrm{~cm}^{-1}$ and $1580 \mathrm{~cm}^{-1}$ were identified as $\mathrm{H}_{\mathrm{g}}$ and $\mathrm{A}_{\mathrm{g}}$ vibration modes of $\mathrm{C}_{60}[12,13]$. The calculated results of F8T2 as shown in Figure 6(c) were conformed two peaks at $1508 \mathrm{~cm}^{-1}$ and $1659 \mathrm{~cm}^{-1}$ as vibration mode of stretching bond of fluoreny in F8T2 polymer. As indicated by an arrow (A) in Figure 5(a), the polarized optical image suggests rich parts of $\mathrm{C}_{60}$ mixed with F8T2 in the black coagulation. The broad peak on base line was identified from fluoresce for a large extent of the $\mathrm{C}_{60}$ powder at
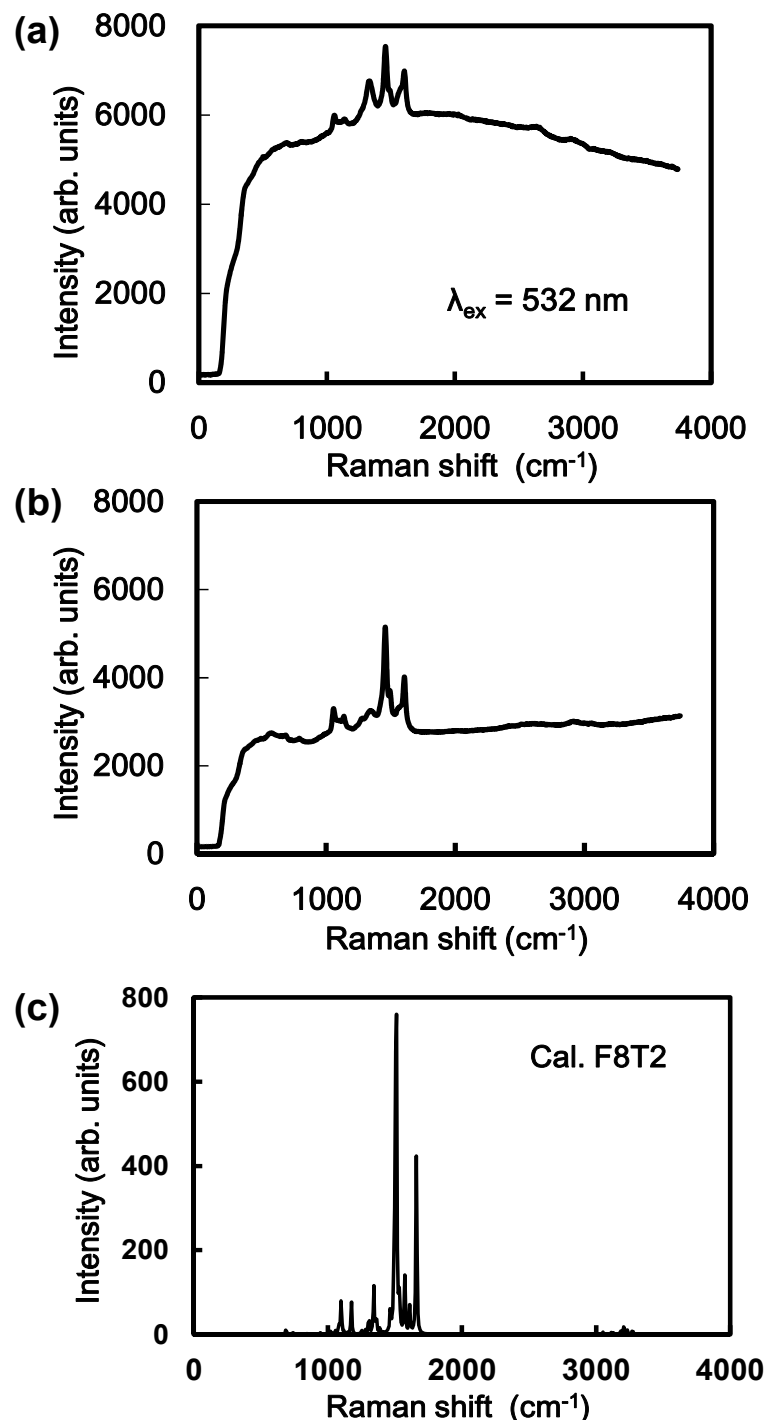

Figure 6. (a), (b) Raman scattering spectra of F8T2/ $\mathrm{C}_{60}$ film as shown in Figures 5(a) and (b). (c) Calculated data of F8T2 monomer by DFT/B3LYP/6-31G (d) using frequency mode.

solid state. As indicated by an arrow (B) in Figure 5(a), Raman mode near the flat part in the polarized optical image indicates a rich segment of F8T2 mixed with $\mathrm{C}_{60}$ in the active layer.

Effect of annealing treatment varied with thermal conditions on morphological behavior of the bulk heterojunction film based on $\mathrm{F} 8 \mathrm{~T} 2 / \mathrm{C}_{60}$ was investigated by atomic force microscopy. The surface morphology of the thin film after annealing at $70^{\circ} \mathrm{C}, 100^{\circ} \mathrm{C}, 130^{\circ} \mathrm{C}, 160^{\circ} \mathrm{C}$ and $190^{\circ} \mathrm{C}$ was shown in Figure 7. The surface morphology was remarkably changed by the heat treatment in the range of glass temperature and liquid crystal transition. At annealing treatment below glass temperature at $110^{\circ} \mathrm{C}$, there was flat surface with island structure with coagulation in the separated phase at solid state. At the 

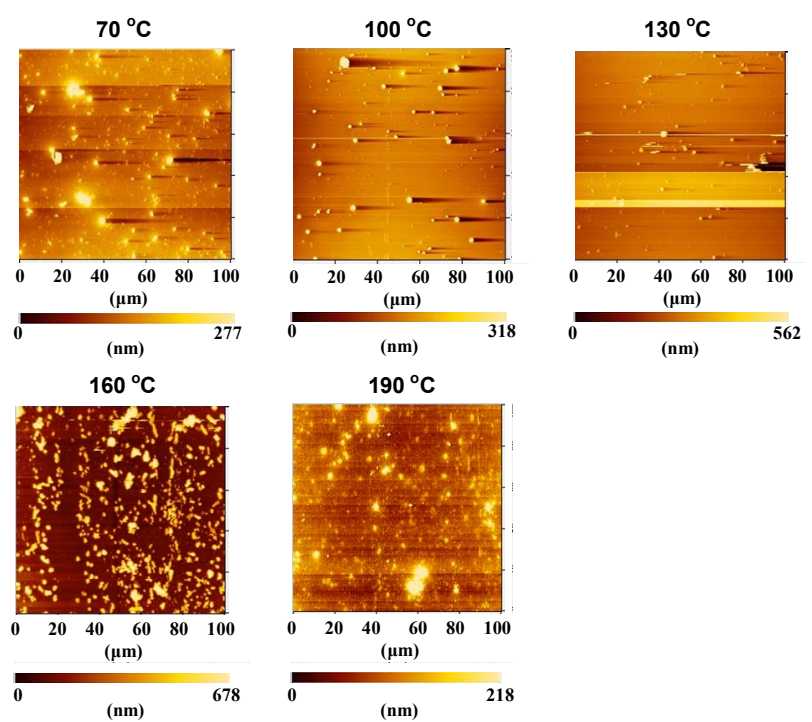

Figure 7. AFM surface images of $\mathbf{F 8 T 2} / \mathrm{C}_{60}$ films after annealing.

annealing above glass temperature, the molecules were disordered with appearance of continuous phase and sea-island like-structure. Further, at annealing near liquid crystal transition at $200^{\circ} \mathrm{C}$, the molecules of F8T2 and $\mathrm{C}_{60}$ were coagulated with each other to form sea-island structure. Remarkable change of morphological behavior varied with annealing condition would influence carrier transport of light-induced generation and excited-carrier and diffusion in the active layer.

Energy levels of the bulk heterojunction solar cells based on F8T2/ $\mathrm{C}_{60}$ were discussed as shown in Figure 8. The phase difference of $p_{z}$ orbital as $\pi$-orbital at HOMO and LUMO indicates bond- and anti-bond molecular orbital. The molecular orbital of P8T2 monomer at HOMO was delocalized on $\pi$-electrons on vinylcarbazole aromatic part combined with thiol component, which would result in donor activity in charge transfer process. The molecular orbital of F8T2 and $\mathrm{C}_{60}$ had wide electron density distributions with energy levels at HOMO and LUMO. Energy levels of F8T2 monomer at HOMO, LUMO and energy gap were estimated to be $-5.1 \mathrm{eV}$, $-1.7 \mathrm{eV}$ and $3.4 \mathrm{eV}$, as compared to reported results for F8T2 to be $-5.5 \mathrm{eV},-3.1 \mathrm{eV}$ and $2.4 \mathrm{eV}$ [7]. The calculated energy gap was converted to be $366 \mathrm{~nm}$ in wavelength, which was red-shifted than the experimental value at $340 \mathrm{~nm}$ in optical absorption as shown in Figure 4. Additionally, the energy levels of $\mathrm{C}_{60}$ at $\mathrm{HOMO}$, LUMO and energy gap were reported to be $-7.3 \mathrm{eV},-4.8$ $\mathrm{eV}$ and $2.5 \mathrm{eV}$, respectively [5]. The calculated energy gap was converted to be $496 \mathrm{~nm}$ in wavelength, which was slightly large as compared with the optical absorption at $460 \mathrm{~nm}$ as shown in Figure 4. The calculated energy levels were based on the isotropic optimized structure without molecular interaction. In actual case of ex-
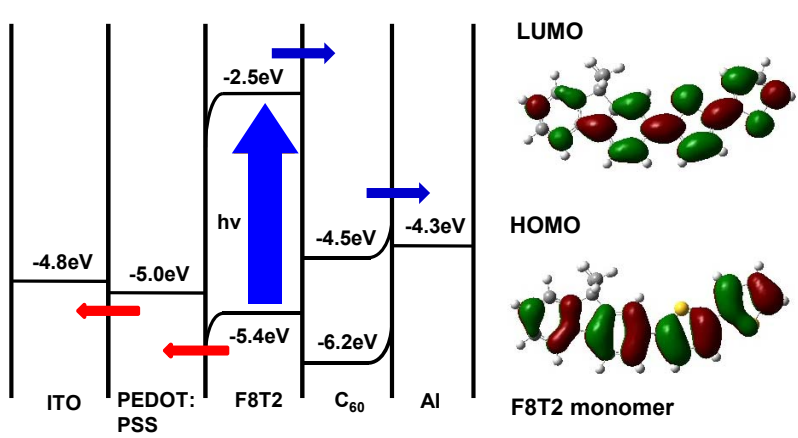

HOMO

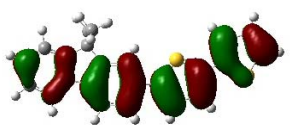

F8T2 monomer

Figure 8. Schematic diagrams of energy levels and molecular orbital of F8T2 monomer at HOMO and LUMO.

perimental results, conjugate effect of polymer with a high degree of polymerization on electronic structure would work delocalization in spin density distribution. The molecular interaction worked together charge transfer would cause a narrowing energy gap between HOMO and LUMO. As shown in Figure 8, previously reported values for the energy levels of F8T2, PEDOT:PSS, Al and ITO were used $[4,7]$. In actual conditions, the energy barrier would be based on state of internal microstructure with molecular interaction at interface.

Photovoltaic mechanism of the heterojunction solar cell will be discussed on the basis of energy levels between HOMO and LUMO. As shown in Figure 8, light irradiation induced to generate charge separations. The excited electron of F8T2 in conducting band slightly diffused and charge-transferred from F8T2 to $\mathrm{C}_{60}$ on active layer and aluminum electrode, and holes in valence band went through PEDOT:PSS layer, and arrived at an ITO substrate. An energy barrier would exist at the semiconductor metal interface. $\mathrm{V}_{\mathrm{oc}}$ of organic solar cells would be related with energy gap between HOMO of F8T2 and LUMO of $\mathrm{C}_{60}$. Control of the energy levels between HOMO and LUMO is important to improve the photovoltaic performance. As described in Ref. [11], the optical behavior based on the energy levels at HOMO and LUMO of $\mathrm{C}_{70}$ instead of $\mathrm{C}_{60}$ was referred to become effective for improving the photovoltaic performance. The optical wavelength of $\mathrm{F} 8 \mathrm{~T} 2 / \mathrm{C}_{60}$ with extent of charge transfer of F8T2 to $\mathrm{C}_{60}$ had slightly influence on the photovoltaic performance with the parameters of $\mathrm{J}_{\mathrm{sc}}$ and $\eta$. The F8T2 thin film in the active layer worked for electronic-donor layer as p-type semiconductor with response of charge-transfer. In the actual situation, recombination and loss of light-induced carrier near inner interface considerably generated energy loss in dependence on the microstructure, since the energy barrier existed around the interface between $\mathrm{F} 8 \mathrm{~T} 2, \mathrm{C}_{60}$ and metal. The heat treatment at annealing in the range of glass temperature and liquid crystal transition will recover the molecular ordering of the internal microstructure, and will guide to increase extent of carrier diffusion with 
inter-diffusion of F8T2 polymer mixed with the $\mathrm{C}_{60}$ phase for improvement of $\mathrm{J}_{\mathrm{sc}}$ in the photovoltaic performance. Furthermore, molecular design and the film preparation condition with mole-ratio of $\mathrm{F} 8 \mathrm{~T} 2$ to $\mathrm{C}_{60}$, thickness, surface morphology in separated phase are important to improve the photovoltaic performance with a wide range of the optical properties.

\section{Conclusion}

Fabrication and characterization of the bulk heterojunction solar cells based on liquid crystal polymer were carried out. The light-induced charge separation with charge transfer was investigated by light-induced current density and optical absorption. Effect of annealing condition on the optical properties and morphological behavior was investigated. The thermal behavior on the optical properties would be originated in molecular ordering worked together molecular interaction with a narrow level between HOMO and LUMO. The morphological behavior of the $\mathrm{F} 8 \mathrm{~T} 2 / \mathrm{C}_{60}$ film had an influence on the annealing condition. The photovoltaic performance and optical properties were depended on the morphological behavior at annealing treatment near glass temperature. The F8T2 thin film worked for electron-donor layer as p-type semiconductor to support charge transfer in active layer at crystal state below glass temperature. Mechanisms of the photovoltaic properties were discussed on the basis of experimental results.

\section{Acknowledgements}

This work was partly supported by a research fund from Takahashi Industrial and Economic Research Foundation.

\section{REFERENCES}

[1] W. Chen, T. Xu, F. He, W. Wang, C. Wang, J. Strzalka, Y. Liu, J. Wen, D. J. Miller, J. Chen, K. Hong, L. Yu and S. B. Darling, "Hierarchical Nanomorphologies Promote Exciton Dissociation in Polymer/Fullerene Bulk Heterojunction Solar Cells," Nano Letters, Vol. 11, No. 2, 2011, pp. 3707-3713. doi:10.1021/n1201715q

[2] Y. Liang and L. Yu, "A New Class of Semiconducting Polymers for Bulk Heterojunction Solar Cells with Exceptionally High Performance," Accounts of Chemical Research, Vol. 43, No. 9, 2010, pp. 1227-1236. doi:10.1021/ar1000296

[3] B. Carsten, J. M. Szarko, H. J. Son, W. Wang, L. Lu, F. He, B. S. Rolczynski, S. J. Lou, L. X. Chen and L. Yu, "Examining the Effect of the Dipole Moment on Charge Separation in Donor-Acceptor Polymers for Organic Photovoltaic Applications," Journal of the American Chemical Society, Vol. 133, No. 50, 2011, pp. 20468-20475. doi:10.1021/ja208642b
[4] T. Oku, K. Nomura, A. Suzuki and K. Kikuchi, "Effect of Perylenetetracarboxylic Dianhydride Layer as a Hole Blocking Layer on Photovoltaic Performance of Poly-Vinylcarbazole: $\mathrm{C}_{60}$ Bulk Heterojunction Thin Films," Thin Solid Films, Vol. 520, No. 7, 2012, pp. 2545-2548. doi:10.1016/j.tsf.2011.10. 163

[5] J. H. Huang, C. Y. Yang, Z. Y. Ho, D. Kekuda, M. C. Wu, F. C. Chien, P. Chen, C. W. Chu and K. C. Ho, "Annealing Effect of Polymer Bulk Heterojunction Solar Cells Based on Polyfluorene and Fullerene Blend," Organic Electronics, Vol. 10, No. 1, 2009, pp. 27-33. doi:10.1016/j.orgel.2008.09.007

[6] P. A. Levermore, R. Jin, X. Wang, J. C. Mello and D. D. C. Bradley, "Organic Light-Emitting Diodes Based on Poly(9,9-Dioctylfluorene-co-Bithiophene) (F8T2)," Advanced Functional Materials, Vol. 19, No. 6, 2009, pp. 950957. doi:10.1002/adfm.200801260

[7] J.-H. Huang, C.-P. Lee, Z.-Y. Ho, D. Kekuda, C.-W. Chu and K.-C. Ho, "Enhanced Spectral Response in Polymer Bulk Heterojunction Solar Cells by Using Active Materials with Complementary Spectra," Solar Energy Materials and Solar Cells, Vol. 94, No. 1, 2010, pp. 22-28. doi:10.1016/j.solmat.2009.02.019

[8] E. Lim, B.-J. Jung, M. Chikamatsu, R. Azumi, K. Yase, L.-M. Do and H.-K. Shim, "Synergistic Effect of Polymer and Oligomer Blends for Solution-Processable Organic Thin-Film Transistors," Organic Electronics, Vol. 9, No. 6, 2008, pp. 952-958. doi:10.1016/j.orgel.2008.06.018

[9] O. Werzera, R. Resela, B. Chernevc, H. Plankc, M. M. Rothmanne, P. Strohriegle, G. Trimmelf, A. Rapalloh and W. Porzioh, "Crystallographic Structure and Morphology of Bithiophene-Fluorene Polymer Nanocrystals," Polymer, Vol. 52, No. 15, 2011, pp. 3368-3373. doi:10.1016/j.polymer.2011.04.063

[10] K. Sagane, M. Shakutsui, T. Tsutsui and K. Fujita, "Polymer Field Effect Transistors of F8T2 Prepared by Evaporative Spray Deposition Using Ultradilute Solution Technique," Journal of Materials Science and Technology, Vol. 21, No. 2, 2008, pp. 193-196.

doi:10.2494/photopolymer.21.193

[11] D. Kekuda, J.-H. Huang, K.-C. Ho and C.-W. Chu, "Modulation of Donor-Acceptor Interface through Thermal Treatment for Efficient Bilayer Organic Solar Cells," Journal of Physical Chemistry C, Vol. 114, No. 6, 2010, pp. 2764-2768. doi:10.1021/jp910023d

[12] M. C. Gather and D. D. C. Bradley, "An Improved Optical Method for Determining the Order Parameter in Thin Oriented Molecular Films and Demonstration of a Highly Axial Dipole Moment for the Lowest Energy $\pi-\pi^{*}$ Optical Transition in Poly(9,9-Dioctylfluorene-co-Bithiophene)," Advanced Functional Materials, Vol. 17, No. 3, 2007, pp. 479-485. doi:10.1002/adfm.200600056

[13] H. Kuzmany, R. Pfeiffer, M. Hulman and C. Kramberger, "Raman Spectroscopy of Fullerenes and Fullerene-Nanotube Composites," Philosophical Transactions of the Royal Society of London, Vol. 362, No. 1824, 2004, pp. 23752406. 